\title{
Correction to: Assessment of microplastic pollution: occurrence and characterisation in Vesijärvi lake and Pikku Vesijärvi pond, Finland
}

\author{
Costanza Scopetani (iD) - David Chelazzi $($ D $~ •$ \\ Alessandra Cincinelli (iD) \\ Maranda Esterhuizen-Londt
}

Published online: 10 December 2019

(C) Springer Nature Switzerland AG 2019

\section{Correction to: Environ Monit Assess (2019) 191:652 \\ https://doi.org/10.1007/s10661-019-7843-Z}

In the original publication, Figure 5 and the related text incorrectly referred to a polyurethane fibre; however, it was a possible PET-polyurethane blend.

Publisher's note Springer Nature remains neutral with regard to jurisdictional claims in published maps and institutional affiliations.

The online version of the original article can be found at https://doi. org/10.1007/s10661-019-7843-z

C. Scopetani $\cdot$ M. Esterhuizen-Londt $(\bowtie)$

Faculty of Biological and Environmental Sciences, Ecosystems and Environment Research Programme, University of Helsinki,

Niemenkatu 73, FI-15140 Lahti, Finland

e-mail: maranda.esterhuizen-londt@helsinki.fi

D. Chelazzi · A. Cincinelli

Department of Chemistry "Ugo Schiff”, University of Florence and Consorzio Interuniversitario per lo Sviluppo dei Sistemi a Grande Interfase (CSGI), Sesto Fiorentino, 50019 Florence, Italy
A. Cincinelli

Department of Chemistry "Ugo Schiff', University of Florence, Sesto Fiorentino, 50019 Florence, Italy

\section{Esterhuizen-Londt}

Helsinki Institute of Sustainability (HELSUS), Fabianinkatu 33, 00014 Helsinki, Finland

\section{Esterhuizen-Londt}

Environmental Safety Group, Joint Laboratory of Applied Ecotoxicology Campus E 7.1, Korean Institute of Science \& Technology (KIST Europe), 66123 Saarbrücken, Germany 